\author{
Military Technical College \\ Kobry El-Kobbah, \\ Cairo, Egypt
}

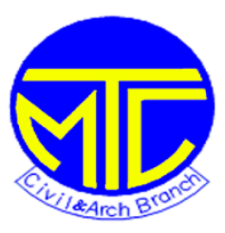

\title{
VALIDATION OF OUTDOOR MICROCLIMATE SIMULATION FOR HOT ARID REGIONS USING A PARAMETRIC WORKFLOW
}

\author{
Ibrahim Elwy $^{1}$ Yasser Ibrahim ${ }^{1}$ Mohammad Fahmy ${ }^{1} \quad$ Mohamed Mahdy $^{1}$ \\ ${ }^{1}$ Architectural Engineering Department, Military Technical College, Cairo, Egypt.
}

\begin{abstract}
.
Outdoor microclimate simulations nowadays are indispensable processes during the early stages of designing sustainable urban forms, which contribute in achieving acceptable thermal comfort degrees, by adopting passive design strategies on both urban and single building scales especially in Hot Arid Regions, which is a substantial climate change mitigation methodology to reduce the impact of urban heat island, and greenhouse gases emissions. Simulations using the numerical microclimate model ENVI-met, despite giving precise results, are time consuming and lacking the availability to be utilized in iterated, form-finding processes. On the other hand, parametric Ladybug Tools, are mainly used as interfaces for validated simulation software such as EnergyPlus, OpenStudio, or OpenFOAM to utilize them in a parametric manner, with a seamless connections among them to finally conduct indoor/outdoor microclimate maps, notwithstanding the absence of some detailed information. This paper compares results from both simulation tools by comparing the microclimate maps conducted from them, and also results at a specific receptor point. In this concern, Thermal comfort metrics like relative humidity, wind speed, air, mean radiant, and physiological equivalent temperatures readings are compared, in which the readings provided an acceptable range of errors, while the parametric workflow generates results for large simulation periods in less time than ENVI-met. The main concern of this validation process is to reach a passable accurate readings for available simulation tools which are aspired among most of sustainable urban form-finding researchers.
\end{abstract}

Keywords: Microclimate, Parametric tools, Outdoor simulation, Validation, Thermal comfort.

\section{Introduction}

Urban inhabitants are predicted to constitute about two-thirds of world population in 2050 [1]. The percentages are increasing, particularly in developing countries which are characterized by hot dry climates, for instance Egypt which is evidenced by a population growth of about 1.7 million per year [2]. Since the middle of the last century, several climate events have been characterized. However, the most observed change in the global climate was the increase of surface air temperature. It's predicted that global mean surface temperature change will likely be $2.6^{\circ} \mathrm{C}$ to $4.8^{\circ} \mathrm{C}$ higher for $2081-2100$ under the worst scenario of the Intergovernmental Panel on 
Climate Change's (IPCC) 5th assessment report [3, 4], the matter that will, with no doubt affect pedestrians' outdoor thermal comfort. Consequently, predesign-based prediction of built environment thermal performance has become of great significance both for building and urban scales [5]. Nonetheless, modelling urban microclimate comprises interdependent parameters with mutual effects resulting in such complexities which, for a reliable results, should be modelled using computational fluid dynamics (CFD) numerical simulations [5, 6]. Moreover, likewise in-situ measurements, urban scale models are often time and resource consuming to simulate even a limited number of days, hence, they are not the appropriate solution for iterative early design process $[\underline{6}, \underline{7}]$. Thus, there is a crucial role for smart urban design workflows to play in the generation of representative maps that precisely demonstrate the thermal performance of spatial scales beyond single buildings, i.e. street canyons. Such workflows are presumed to enable the simulation of iterative design solutions based on multiple meteorological inputs, in a relatively shorter duration compared to CFD simulation software [8].

In the same context, the last decade has been evidenced by the emergence of parametric tools which have become a part and parcel of the architectural design workflow. At the same time, regardless their limited integration to early design phase, computational models have been verified to numerically simulate the outdoor urban microclimate with an acceptable degree of agreement with field measurements [ $[\underline{6}, \underline{9}]$. Having the notion of the graphical representation along with comparative assessment of design alternatives at the early design phase [10], CFD simulations coupled with parametric design workflows can give an integrated decision support on various thermal conditions on a performance base [11]. For doing so, this paper investigates the integration of Ladybug tools, the environmental applications within the parametric design interface of Grasshopper 3D, and ENVI-met v.4, the CFD simulation tool to validate the multistage parametric design workflow to support the decision-making process in the predesign phase.

\section{Methods}

By utilizing the parametric platform of Grasshopper 3D, Ladybug Tools connectsvarious validated building performance simulation engines, i.e. EnergyPlus, OpenStudio, OpenFOAM, Radiance and Daysim, with an easy to handle graphical algorithm editor interface of Grasshopper, which allow designers to manipulate design modifications according to the model's environmental performance[12]. Amalgamation of these validated engines and environmental data-sets can form an integrated approach to investigate the outdoor microclimate of the built environment, and the assessment of thermal comfort for a period of the year in a relatively small simulation time, which is a substantial factor for urban form finding and optimization process through different design iterations.

On the other hand, within the field of urban climatology and its environmental interactions, ENVI-met, as a 3D non-hydrostatic numerical model does transcend conventional CFD packages. It works conveniently to assess thermal comfort, all meteorological parameters and all urban surface and vegetation (surface-plant-air) thermal interactions and heat exchange processes on the fundamental laws of fluid dynamics and thermodynamics [13]. ENVI-met has been acknowledged as suitable for complex models [14], and its results were validated with respect to humidity [15] and global radiation [16]. Emmanuel, Rosenlund [17] have selected ENVI- 
met as the most suitable model for analysing thermal comfort within the street canyon. Shahidan [18] proved reasonable agreement between field measurement and ENVI-met simulations.

\section{Methodology}

The study has been conducted in three main phases (Figure 1); the CFD simulation approach using ENVI-met software, the alternative parametric simulation phase using Ladybug Tools, and finally, the comparison phase using the image based comparison between microclimate maps of thermal comfort in Physiological Equivalent Temperature (PET) conducted from both simulation phases, and error calculations for the results of a definded receptor at a specific point at the same location.

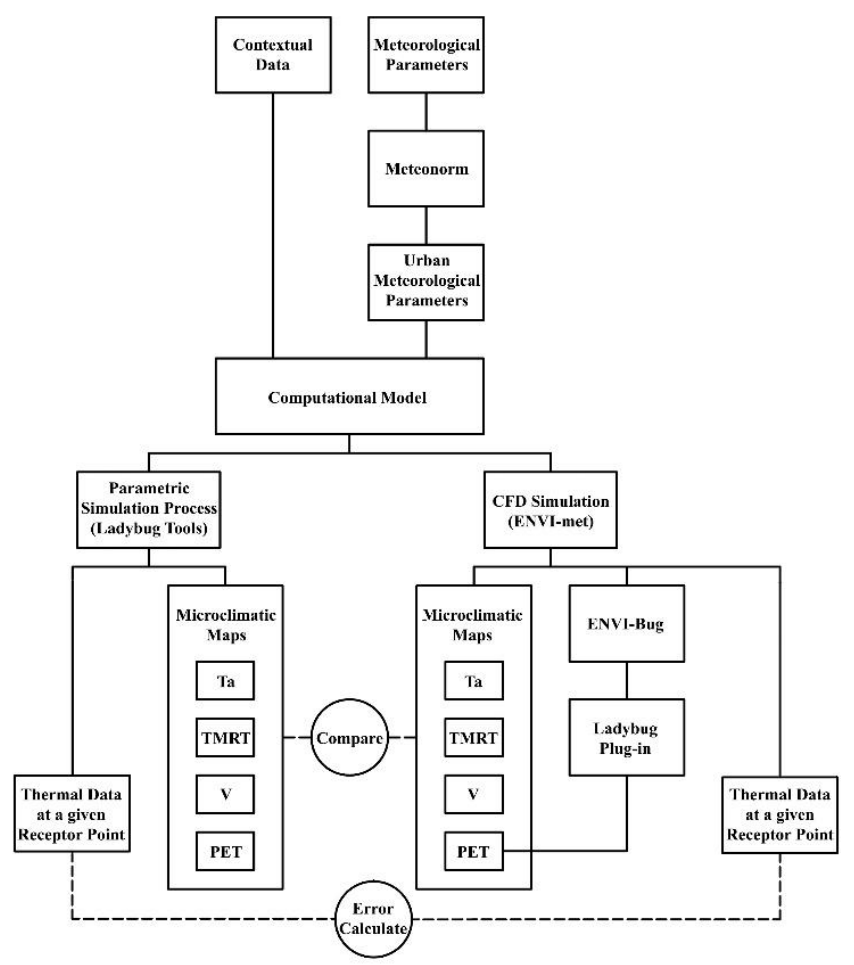

Figure 1. Methodology flowchart showing the main processes and the interactions among them

\subsection{CFD simulation by ENVI-met software}

This phase was performed to account for the microclimatic meteorological performance of the street canyon of interest by calculating the main output parameters and generating visual maps by means of LEONARDO, the built-in tool of ENVI-met. For doing so, an area of 170x110 meters was modelled to account for the climatic interactions between the canyon and the neighbouring environment (Figure 2). As the built environment includes on conventional skeleton structures and pavements, building materials properties were expressed using the default database of ENVI-met. Table 1 shows the data entry for the model's area. 


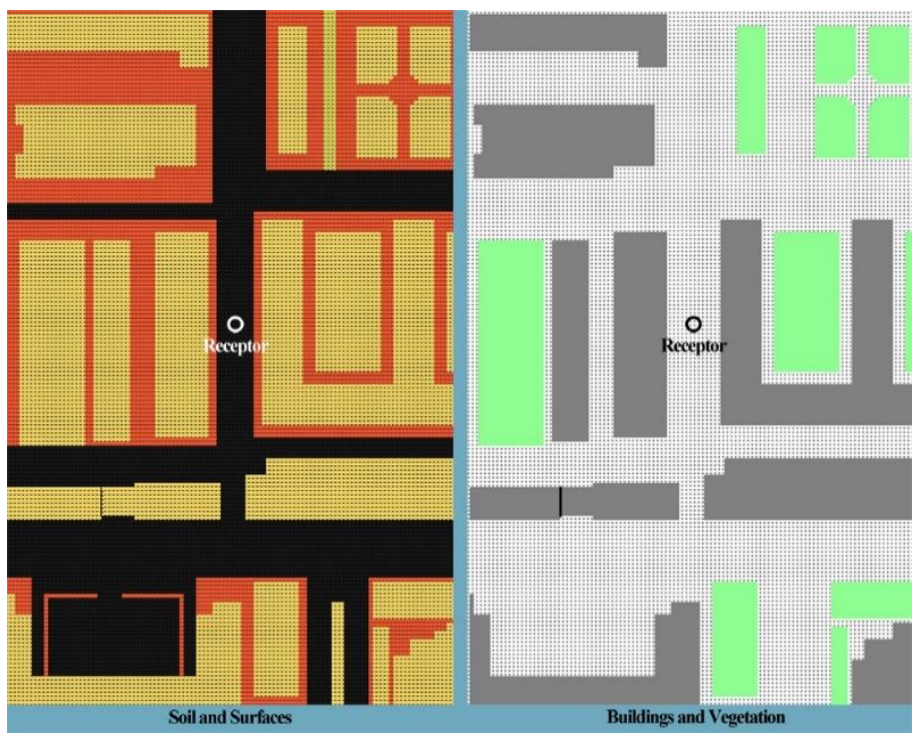

Figure 2. ENVI-met model area.

Table 1. Data entry for model area.

\begin{tabular}{ll}
\hline Parameter & Value \\
\hline Main area grid boundary & $\mathrm{X}=110, \mathrm{y}=170, \mathrm{z}=30$ \\
Grid scale & $\mathrm{dx}=1, \mathrm{dy}=1, \mathrm{dz}=3$ \\
Soil profile for all grids & Sandy soil, brick roads (albedo 0.3), and asphalt (albedo 0.2) \\
Vegetation & Grass only (albedo $=0.2)$ \\
Nesting grids & 3 (unsealed loamy soil) \\
Wall materials & Burned bricks, thickness $=0.3$, albedo=0.4 \\
Roof materials & Roofing tiles, thickness $=0.05$, albedo $=0.5$ \\
\hline
\end{tabular}

In order to adequately represent the meteorological conditions of the urban context and its effect on the thermal performance of street canyons, the original EnergyPlus Weather (EPW) file that includes data recorded in Cairo international airport weather station, was converted thanks to METEONORM [19] into a new EPW. Data obtained from the new EPW file were inputted to the configuration wizard of the simulation as shown in table 2 .

Table 2. Input parameters for configuration.

\begin{tabular}{ll}
\hline Parameter & Value \\
\hline Air temperature $(\mathrm{Ta})\left({ }^{\circ} \mathrm{C}\right)$ & 22.9 \\
Wind speed $(\mathrm{m} / \mathrm{s})$ & 0.70 \\
Wind direction & $262(0$ from North $)$ \\
Relative humidity $(\mathrm{RH})(\%)$ & 64 \\
Specific humidity $(\mathrm{g} / \mathrm{kg})$ & 11.15
\end{tabular}


Lateral boundary conditions $\quad$ Open for Ta and RH, Forced for Turbulence

\subsection{Outdoor thermal comfort simulation using Ladybug Tools}

In the second phase, a set of simulation processes using validated engines were combined togetherto eventually conduct thermal comfort microclimate maps. While the main inputs for the simulation were the same urban geometry, and the modified weather file using METEONORM software.Grasshopper and Rhinoceros 3D software were used to model the geometry of the same study area of interest. Noting that ENVI-met software usesthe grid squares for modelling, where buildings cannot have any modelling details. This is more likely a great advantage for the parametric approach of investigation, to simply conduct thermal comfort microclimate maps for sites with detailed or complex building forms rather than the pixels shaped models.

By utilising the parametric components of Ladybug Tools, the whole microclimate simulation workflow was generated in multiple phases, each phase is considered as a separate simulation process, where each process conduct a climatic factor that affects pedestrian thermal comfort. The first process was to simulate wind speed (V) at a certain height using the validated CFD simulation software "OpenFOAM" [20], which was linked by Grasshopper using the Butterfly plug-in. Wind factors (WF) at each grid point for every wind direction (Figure 3) were generated by dividing the simulated $\mathrm{V}$ by the initial wind speeds at each direction, which were chosen to be 9 , i.e.every 40 degrees, since it was previously recommended to investigate hourly microclimates of an urban area. The initial wind speeds were determined form the statistical analysis of the weather file of Cairo, as the average wind speed at each direction. WFs in combining with the meteorological wind speeds, could eventually conduct hourly wind speeds at each grid point for the entire year. 


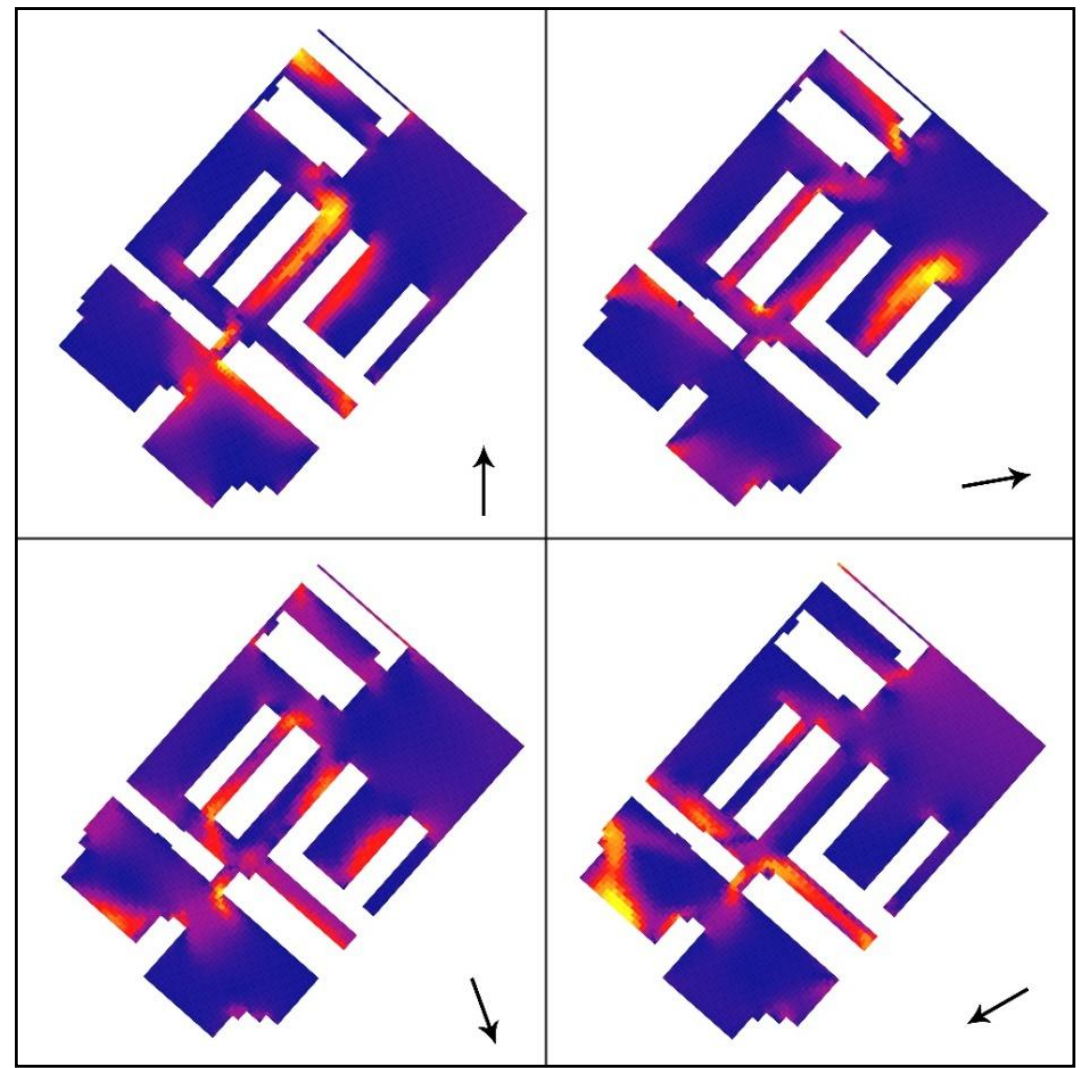

Figure 3. Four different WF maps for wind blowing from different directions.

The second simulation process was using Honeybee Plugin that interfaces the simulation engine of EnergyPlus, to simulate the external surfaces temperature.In this process, buildings were divided into zones per each floor, and the ground zones' surfaces were subdivided into smaller fragments with dimensions not exceed $5 \mathrm{~m} \times 5 \mathrm{~m}$, to ensure minimum variations of temperature between surfaces. These surfaces temperatures were used in the next process for calculating Mean Radiant Temperature (Tmrt) combined with long-wave radiations from sky, and shortwave solar radiations. Finally the outputs of the previous processes were merged to calculate thermal comfort in terms of PET for temperature climates and produce its visual microclimate maps.

\subsection{Error calculations and comparing phase}

With respect to the specific point (receptor) defined in each software, the four main microclimatic output parameters (Ta, Tmrt, V, PET) were compared to investigate the level of accuracy at which the hybrid parametric workflow using Ladybug Tools are able to present the microclimatic parameters. For doing so, three main error calculations were performed, namely the Root Mean Squared Error (RMSE), the Coefficient of Determination $\left(\mathrm{R}^{2}\right)$, and the Index of Agreement (IA). Knowing that the optimum value for each error is $(0,1$, and 1) respectively, the comparison has revealed a good level of agreement between the ENVI-met (we refer to as the observed) and the Ladybug tools (we refer to as the predicted) results. Table 3 shows each comparison and the corresponding error calculated. 
Table 3. Error calculations for the observed-predicted results.

\begin{tabular}{lccc}
\hline Parameter & RMSE & $\mathrm{R}^{2}$ & IA \\
\hline Air Temperature (Ta) & 1.38 & 0.98 & 0.90 \\
Mean Radiant Temperature (Tmrt) & 10 & 0.61 & 0.88 \\
Wind Speed (V) & 0.26 & 0.11 & 0.09 \\
\cline { 2 - 3 } Physiological Equivalent Temperature (PET) & 5.43 & 0.71 & 0.91 \\
\hline
\end{tabular}

Regarding the RMSE, a solely recognizable difference in one hour was enough for the predicted curve to deviate (red boxed). Moreover, due to the lower initial wind speeds, the output curves showed a poor agreement where such comparison would be of good consistency if performed in a gusty day. Otherwise, $\mathrm{R}^{2}$ and IA values were sufficient to indicate a good agreement between the observed and the predicted curves.

\section{Results and discussion}

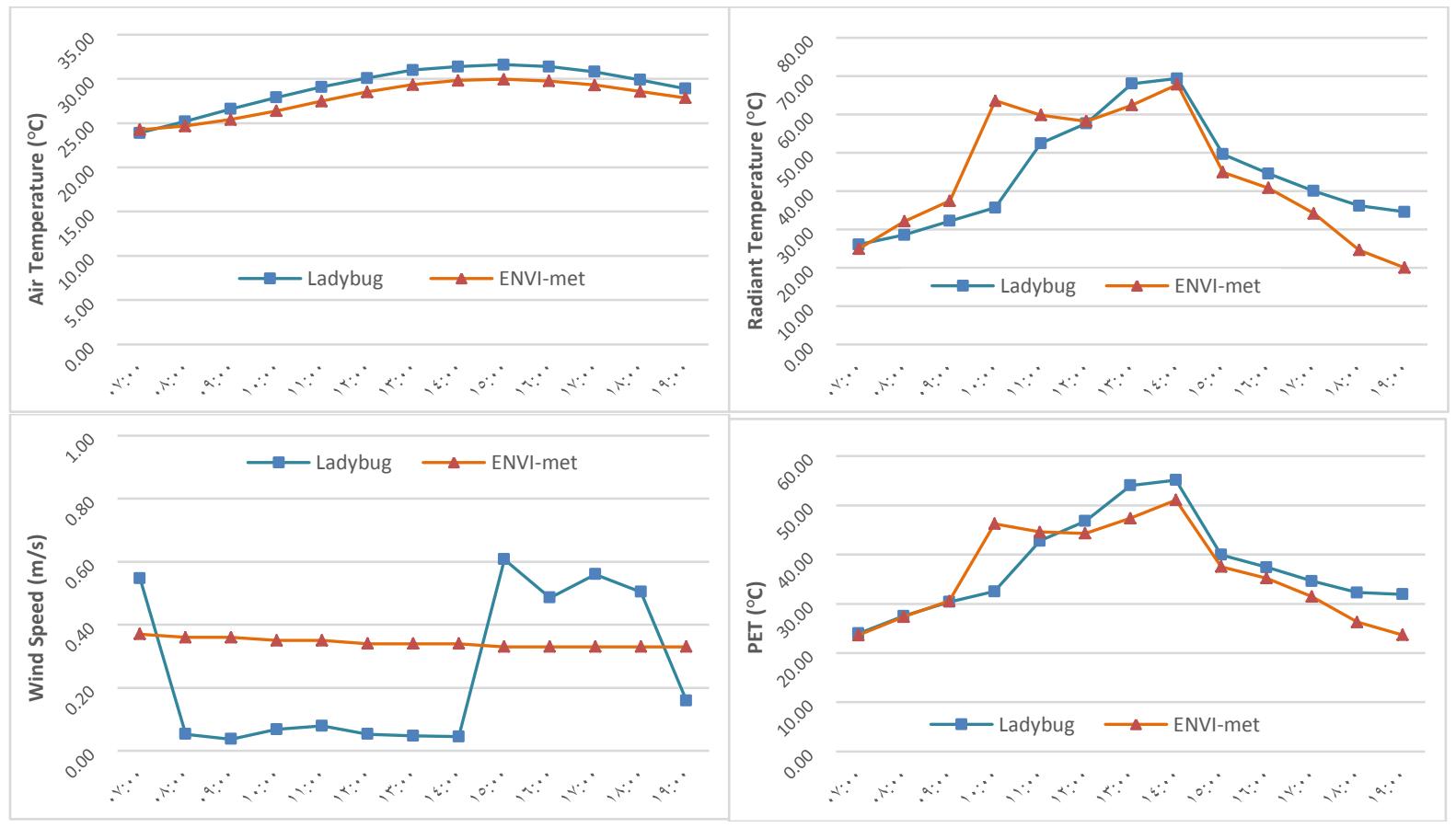

Up-left: Figure 4. Air temperature comparison, Up-right: Figure 5. Radiant temperature comparison, Down-left: Figure 6. Wind speed comparison, and Down-right: Figure 7. PET comparison.

As previously mentioned, figures 4, 5, and 7 shows a good agreement between the observed and the predicted values. Air temperature curves started nearly at the same value, rose gradually at the same rate and fall again close to each other. The temperature difference did not exceed the $1.65{ }^{\circ} \mathrm{C}$ limit within the whole simulation interval (figure4). Moreover, Tmrt curves started also at the same value, rose gradually, however, ENVI-met has overestimated the global radiation and 
caused a noticeable difference at $10: 00$ of $27{ }^{\circ} \mathrm{C}$, then returned to match again and fall down though with different rates, the matter that caused the curves to deviate again and differs by 14.5 ${ }^{\circ} \mathrm{C}$ (figure5). Similar to the radiant temperatures, PET curves almost had the same trend. This is most likely attributed to the calculation of ENVI-met PET values via the parametric tool, ENVIbug. However, with less difference of about $13.5^{\circ} \mathrm{C}$ at 10:00 and $8.2{ }^{\circ} \mathrm{C}$ at 19:00 (fig 7), the values give a good indication of accuracy.Wind speeds, on the other hand, showed a completely different trend, though the maximum difference did not exceed $0.3 \mathrm{~m} / \mathrm{s}$ (fig 6). This is attributed, as mentioned above, to the low initial wind speed which has lead both tools to malfunction and result in such poor correlation.

Furthermore, within each simulation phase that have been conducted through this research, each tool has given readings that indicate outdoor thermal behaviour in microclimate maps. Simple comparisons of visual maps that indicateTa, Tmrt, V, and PET, were made to highlight the accuracy of the hybrid parametric tools' final results for each hour of the selected simulation period (figures 8-11).

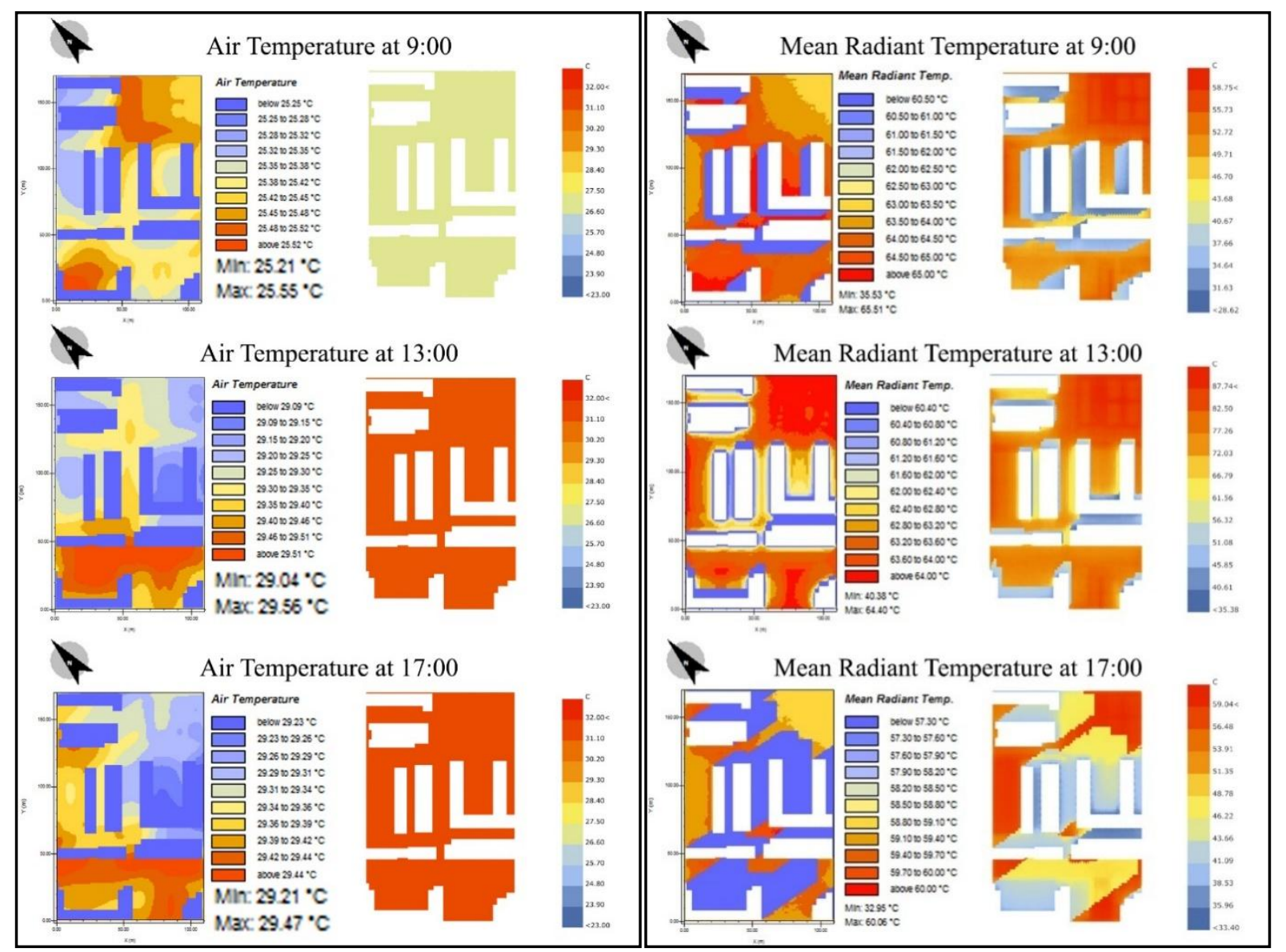

Left: Figure 8. Ta thermal maps comparison, Right: Figure 9. Tmrt thermal maps comparisons

It is worth noting that the legends of the maps were adjusted manually in order to clearly demonstrate the consistency of the maps. As shown in the figure8, Ta maps comparisons 
represented a poor correlation, despite the fact that values from both simulations are convergent.The whole grid of Ladybug Tools had the same Ta value, and therefore, maps are limited to a single color per each hour, while in ENVI-met, maps are colored according to different Ta values even though the difference between minimum and maximum values does not exceed $0.5^{\circ} \mathrm{C}$. On the other hand, in figure9 Tmrt maps are with few differences recognized as the Ladybug tools have not accounted for areas at low albedo (grass areas), specially at noon where Tmrt values reached more than $85^{\circ} \mathrm{C}$ in some places.

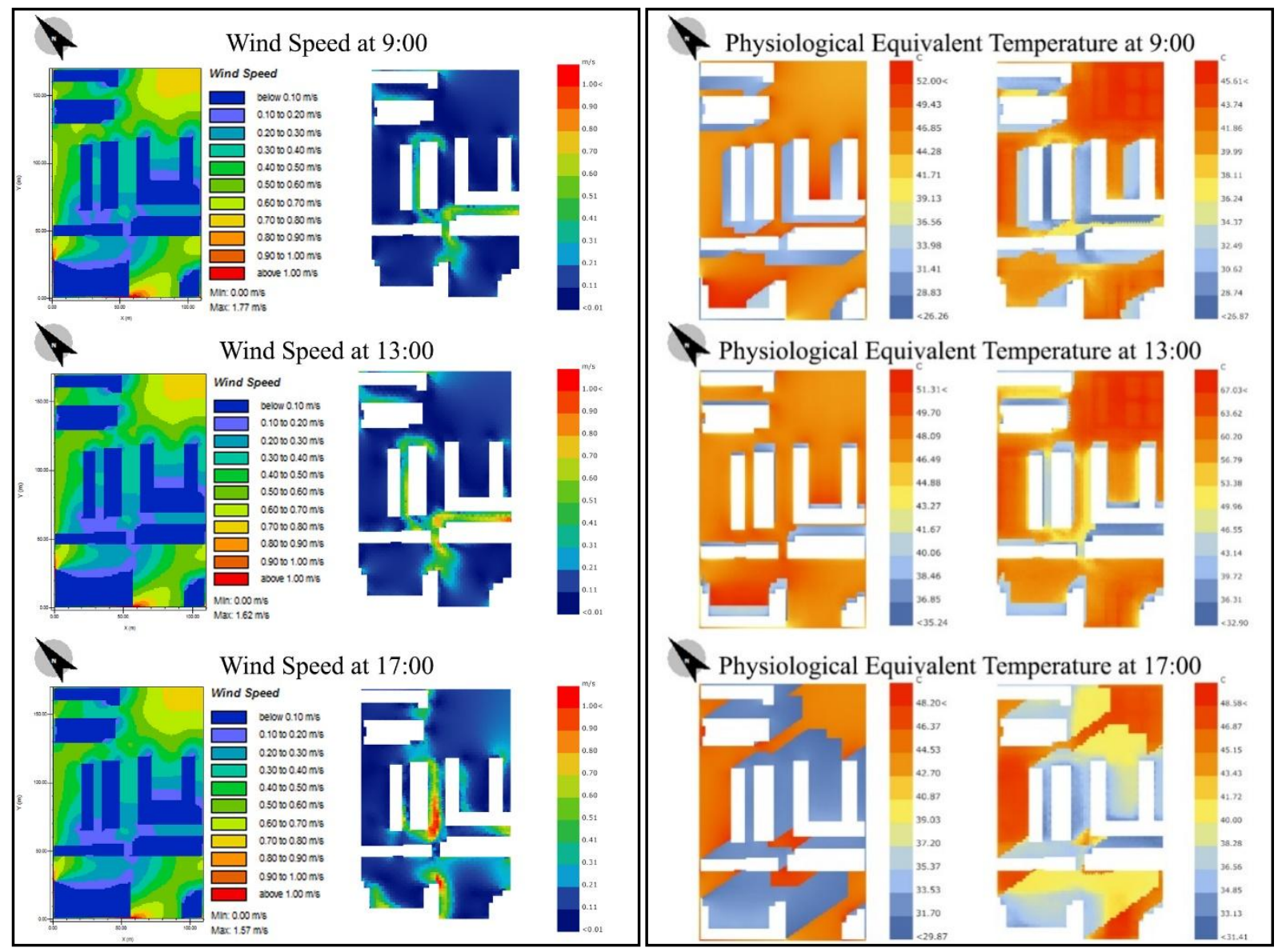

Left: Figure 10. V thermal maps comparison, Right: Figure 11. PET thermal maps comparisons

Figure 10 represents comparisons of $\mathrm{V}$ maps, although $\mathrm{V}$ did not exceed $1 \mathrm{~m} / \mathrm{s}$, but the difference in maps were due to the dependence of ENVI-met on a single wind direction for the whole simulation period (initial wind direction), where an insignificant change between maps would appear. While in the hybrid approach of Ladybug Tools, wind speeds accounted for meteorological wind directions, as wind could blow from different locations among simulation period, where meteorological wind speed is multiplied by its corresponding WF. This WF method of more than wind direction is presumably a better way for predicting $\mathrm{V}$, and wind comfort in urban microclimates.Finally, in figure 11PET maps are in close proximity, and almost the same values are visualized within the whole site, conforming to the values obtained by the 
receptor points, with a difference in the afternoon, where shaded areas have a bit higher PET degrees in the hybrid approach than ENVI-met. It's worth noting that PET values for ENVI-met simulation process were calculated using ladybug thermal comfort indices component, where points' data were driven from reading grid results using the connection tool between ENVI-met and Ladybug.

\section{Conclusion and future research}

This study has investigated and compared the microclimatic simulation readings using the validated, and fully-integrated environmental software, ENVI-met, and the hybrid parametric workflow of Ladybug Tools. It was shown that a very good agreement between results from both simulation processes, especially in the final results of PET maps and receptor point data. Error calculations proved the two simulation tools to be in close proximity.In conclusion, results have shown that differences in Ta, Tmrt, V, and PET receptor readings, andthermal maps demonstrated that the workflow using Ladybug tools are strongly efficient in the presentation of outdoor microclimatic parameters numerically and visually, and hence they would have a great role to play at the early design stages, which help to create multiple design iterations, and work as a design guideline for architects and urban planners to optimize their urban design based on a thermal performance criteria.It is undoubtable, however, that the validation of this parametric simulation workflow against in situ field measurements in the future research is crucialin order to represent the real climatic conditions of the urban environment.

\section{References}

1. UN, World Urbanization Prospects: The 2014 Revision, Highlights. 2014, Department of Economic and Social Affairs Population Division: New York. p. 32.

2. UN, World Population Prospects: The 2015 Revision, Key Findings and Advance Tables. 2015, Department of Economic and Social Affairs Population Division: New York. p. 66.

3. Fahmy, M., Y. Ibrahim, and H. Mokhtar, Optimization of neighbourhood green rating for existing urban forms through mitigation strategies: A case study in Cairo, Egypt, in Proceedings of 33rd PLEA International Conference, L. Brotas, S. Roaf, and F. Nicol, Editors. 2017, NCEUB 2017: Edinburgh. p. 247-254.

4. IPCC, Climate change 2014: synthesis report. Contribution of Working Groups I, II and III to the fifth assessment report of the Intergovernmental Panel on Climate Change, ed. C.W. Team, R.K. Pachauri, and L.A.M. (eds.). 2014, Switzerland: Intergovernmental Panel on Climate Change.

5. Fahmy, M., et al., On the green adaptation of urban developments in Egypt; predicting community future energy efficiency using coupled outdoor-indoor simulations. Energy and Buildings, 2017. 153: p. 241-261.

6. Salata, F., et al., Urban microclimate and outdoor thermal comfort. A proper procedure to fit ENVImet simulation outputs to experimental data. Sustainable Cities and Society, 2016. 26: p. 318-343.

7. Mackey, C., et al., Wind, Sun, Surface Temperature, and Heat Island: Critical Variables for HighResolution Outdoor Thermal Comfort. 2015.

8. Yi, H., R.S. Srinivasan, and W.W. Braham, An integrated energy-emergy approach to building form optimization: Use of EnergyPlus, emergy analysis and Taguchi-regression method. Building and Environment, 2015. 84: p. 89-104. 
9. Forouzandeh, A., Numerical modeling validation for the microclimate thermal condition of semiclosed courtyard spaces between buildings. Sustainable Cities and Society, 2018. 36: p. 327-345.

10. Attia, S., et al. "Architect friendly": A comparison of ten different building performance simulation tools. in Proceedings of 11th International Building Performance Simulation Association Conference and Exhibition. 2009. International Building Performance Simulation Association (IBPSA).

11. Peronato, G., et al. Integrating urban energy simulation in a parametric environment: $a$ Grasshopper interface for CitySim. in PLEA 2017 Edinburgh-Design to Thrive. 2017.

12. Roudsari, M.S., M. Pak, and A. Smith, Ladybug: a parametric environmental plugin for grasshopper to help designers create an environmentally-conscious design, in Proceedings of the 13th international IBPSA conference. 2013: Lyon, France.

13. Bruse, M., Assessing urban microclimate from the user's perspective-Multi-agent systems as a new tool in urban biometeorology. Ann. Meteorol, 2005. 41(1): p. 137-140.

14. Moonen, P., et al., Urban Physics: Effect of the micro-climate on comfort, health and energy demand. Frontiers of Architectural Research, 2012. 1(3): p. 197-228.

15. Fahmy, M., S. Sharples, and M. Yahiya, LAl based trees selection for mid latitude urban developments: A microclimatic study in Cairo, Egypt. Building and Environment, 2010. 45(2): p. 345-357.

16. Ali-Toudert, F., Dependence of Outdoor Thermal Comfort on Street Design in Hot and Dry Climate, in Berichte des Meteorologischen. 2005, Institutes der Universität Freiburg.

17. Emmanuel, R., H. Rosenlund, and E. Johansson, Urban shading-a design option for the tropics? A study in Colombo, Sri Lanka. International Journal of Climatology, 2007. 27(14): p. 1995-2004.

18. Shahidan, M.F., Potential of Individual and Cluster Tree Cooling Effect Performances through Tree Canopy Density Model Evaluation in Improving Urban Microclimate. Current World Environment, 2015. 10(2): p. 398.

19. METEONORM. Irradiation Data for Every Place on Earth. 2018 1/25/2018]; Available from: www.meteonorm.com.

20. Robertson, E., et al., Validation of OpenFOAM Numerical Methods and Turbulence Models for Incompressible Bluff Body Flows. Computers and Fluids, 2015. 